\title{
Pengaruh Kecepatan Putar Indentor Las Gesek Puntir (Friction Stir Welding) Terhadap Kualitas Hasil Pengelasan Alumunium 1100-H18
}

\author{
Irza Sukmana, Ade Sustiono \\ Jurusan Teknik Mesin, Fakultas Teknik, Universitas Lampung \\ Gedung H, Lt. 2 Jalan Prof. Soemantri Brojonegoro 1, Bandar Lampung 35143 \\ Telephone / Facsimile: (0721) 704947 \\ E-mail: irza.sukmana@eng.unila.ac.id
}

\begin{abstract}
Abstrak
Material Aluminum (Al) dan paduannya telah banyak digunakan secara luas diberbagai bidang industri. Aluminum memiliki sifat korosi yang baik, namun permasalahan Aluminum adalah sulitnya proses penyambungan, karena adanya lapisan oksida di permukaan logam. Teknologi pengelasan gesek puntir (friction stir welding, FSW) merupakan alternatif yang potensial untuk diaplikasikan pada aluminum. Dalam penelitian ini, digunakan mesin freis vertikal Milko-12 yang telah difasilitasi indentor las. Proses pengelasan dilakukan pada bahan Aluminum 1100-H18 untuk 4 (empat) macam parameter kecepatan rotasi indentor (Rt) yang berbeda, yaitu:352, 490, 653, dan $910 \mathrm{rpm}$, sedangkan kecepatan transversal indentor (V) tetap: $20 \mathrm{~mm} / \mathrm{menit}$. Pengujian kualitas hasil pengelasan dilakukan dengan analisa sifat mekanik dan data metalografi. Hasil pengujian kualitas las menunjukkan bahwa semakin tinggi kecepatan rotasi indentor (Rt), akan meningkatkan kekuatan tarik lasan hingga titik maksimumnya pada saat Rt=653rpm, dimana kekuatan tariknya sebesar $107 \mathrm{MPa}$. Daerah patah lasan adalah pada logam dasar (Base Metal, BM), menunjukkan bahwa mesin freis konvensional Milko-12 dapat digunakan untuk proses pengelasan puntir gesek (FSW) pada material Aluminum.
\end{abstract}

Kata Kunci: Aluminum 1100-H18, las puntir gesek, Milko-12, mesin freis vertikal.

\begin{abstract}
Aluminum and their alloys have been applied in many industrial sectors. Although it shows a good corrosion properties, however welding process of aluminum still a challenge as it covered by oxide layer on the surface. Friction Stir Welding (FSW) technology gives a potential chance to be used for joining process of aluminum. In this study, we use a vertical milling machine Milko-12 that has been utilized with indentor of FSW process for Aluminum 1100-H18 at 4 (four) different rotation speed (Rt), i.e.: 352, 490, 653, and 910 rpm and constant transversal speed (V) 20mm/minutes. Based on mechanical properties and metallography data of welded materials, the higher the Rt the higher the tensile strength. Rt of $653 \mathrm{rpm}$ results the highest tensile strength of $107 \mathrm{MPa}$. The crack areas of all welded metals are at base metal (BM) concluded that our vertical milling machine Milko-12 can be utilized for friction stir welding (FSW) process for Aluminum.
\end{abstract}

Keywords:Aluminum 1100-H18, friction stir welding, Milko-12, vertical milling machine.

\section{PENDAHULUAN}

Aluminum yang memiliki rumus kimia $\mathrm{Al}$, dikenal sebagai logam ringan yang memiliki sifat ketahanan korosi dan konduktor listrik yang baik. Aluminum (Al) memiliki masa jenis sebesar $2,71 \mathrm{mg} / \mathrm{m}^{3}$ atau sekitar $1 / 3$ (satu per tiga) masa jenis baja atau tembaga [1]. Dengan keistimewaan sifat mekanik tersebut, aluminum dan paduannya banyak diaplikasikan sebagai material konstruksi ringan (light-weight structure), di industri kimia, makanan, listrik, transportasi dan aeronautika.

Dalam aplikasi material Aluminum di berbagai bidang industri tersebut, sering diperlukan proses penyambungan. Aluminum dan paduannya memiliki sifat mampu las yang rendah bila dibandingkan dengan logam lain, terutama baja. Tingkat afinitas yang tinggi terhadap oksigen menyebabkan aluminum mudah berikatan dengan oksigen dan membentuk lapisan oksida $\mathrm{Al}_{2} \mathrm{O}_{3}$ di permukaan logam. Lapisan $\mathrm{Al}_{2} \mathrm{O}_{3}$ memiliki titik cair yang tinggi atau sekitar $2050^{\circ} \mathrm{C}$ dan jauh lebih tinggi jika dibandingkan dengan titik cair aluminum dan paduannya yang hanya sekitar $700^{\circ} \mathrm{C}[2]$.

Oleh karena itu, aluminum dan paduannya hanya dapat dilas dengan menggunakan teknik pengelasan tertentu, seperti: TIG (tungsten inert gas), pengelasan titik (spot welding) untuk pelat aluminum 
yang tipis, dan pengelasan tanpa pencairan atau non cair (solid-state welding). Teknik pengelsasan noncair sangat cocok diaplikasikan untuk aluminum dan paduannya bentuk pelat maupun poros, karena dapat menghindari cacat las karena proses oksidasi. Teknik pengelasan gesek puntir (friction stir welding, FSW) termasuk katagori pengelasan jenis non-cair.

Penelitian ini bertujuan untuk menguji aplikasi dan potensi utilisasi mesin freis vertikal Milko-12 untuk melakukan pengelasan gesek puntir (FSW). Uji tarik, struktur makro dan mikro, serta uji keras mikro dilakukan pada meterial Aluminum 1100-H18 hasil pengelasan sebagai evaluasi potensi utilisasi Milko12 untuk proses FSW aluminum dan paduannya.

\section{TINJAUAN PUSTAKA}

Aluminum seri 1xxx merupakan paduan aluminum yang sering digunakan untuk berbagai aplikasi di dunia industri, terutama sebagai bahan konstruksi ringan (light-weight structure) pada tanki dan pipa kimia, mesin otomotif, dinding pesawat, dan berbagai aplikasi lain. Seri 1100 memiliki kadar Al minimum 99\%, dan H18 menunjukkan nomenklatur khusus yang diberikan oleh ASM International berdasarkan sifat seri $1100-\mathrm{H} 18$ yang meiliki kekuatan tarik dan sifat creep yang relatif lebih tinggi dibandingkan seri asalnya (1100-O) [3].

Aluminum dan paduannya memiliki sifat mampu korosi yang lebih baik bila dibandingkan dengan baja karbon. Namun, Al memiliki panas jenis dan daya hantar panas yang relatif lebih tinggi sehingga menyebabkan bahan konstruksi aluminum memiliki mampu las (weldability) yang lebih buruk dibandingkan baja karbon. Untuk proses penyambungan aluminum pelat tebal dan poros umumnya menggunakan las TIG (tungsten inert gas) dengan polaritas dan arus bolak-balik frekuensi tinggi [2].

Dengan teknologi TIG, lapisan oksida yang terbentuk dipermukaan aluminum akan dipecah dan dibersihkan oleh busur listrik yang dihasilkan. Teknik pengelasan lain yang dapat digunakan adalah las gas, las busur elektroda terbungkus, dan las sinar elektron. Namun, teknik pengelasan tersebut memerlukan fluks yang mengandung unsur khlorida dan fluorida, untuk menghilangkan lapisan oksida yang ada. Kelemahan teknik pengelasan dengan menggunakan fluks pada aluminum adalah berat jenis aluminum yang rendah, sehingga berpotensi mengakibatkan fluks tenggelam dan tertinggal didalam logam dan menjadi penyebab terjadinya cacat pada logam las [2-3].

Terbatasnya teknologi pengelasan yang dapat diaplikasikan untuk proses pengelasan aluminum telah memberik peluang implementasi teknologi pengelasan tanpa pencairan atau non-cair (solid-state welding), diantaranya adalah las gesek (friction welding, FW) dan las gesek puntir (friction stir welding, FSW). Teknik pengelasan non cair pada aluminum dan paduannya dapat mengeliminir terjadinya retak panas dan rongga udara terjebak, deformasi dan penyusutan rendah, dan tidak memerlukan filler metal dan gas pelindung [4].

Proses FSW menggunakan perangkat pengelasan yang relatif sederhana dan dapat dilakukan dengan menggunakan mesin freis vertikal untuk memutar indentor las yang akan berfungsi sebagai pemberi energi panas gesekan (friction) dan sekaligus pengaduk (stir), sebagaimana dijelaskan dalam Gambar 1.
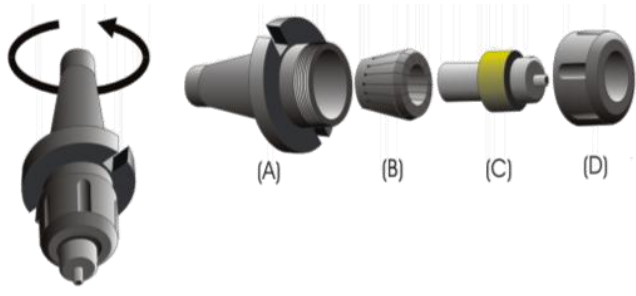

Gambar 1. Perangkat FSW pada pemegang pahat mesin freis (a-b) arbor/collet, (c) indentor (d) klem.

\section{METODE PENELITIAN}

Dalam penelitian ini digunakan Mesin Freis vertical Merek Milko-12 dengan bentuk dan geometri indentor FSW sebagaimana Gambar2. Material indentor las harus memiliki titik cair yang lebih tinggi dibandingkan logam las, agar selama proses pengelasan tidak terjadi pencairan dan pencampuran logam indentor. Dalam penelitian ini digunakan indentor dari bahan baja karbon sedang.

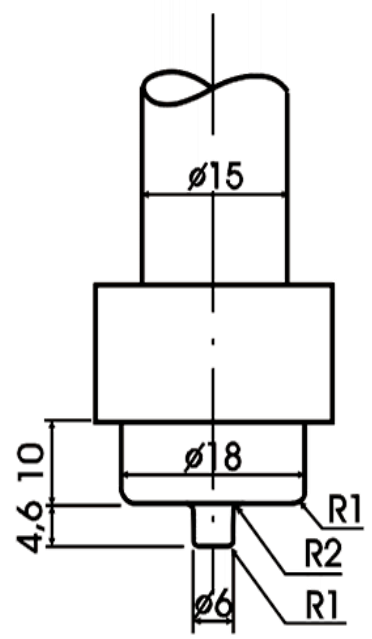

Gambar 2. Spesifikasi geometri indentor FSW 
Komposisi kimia bahan aluminum seri 1100H18 yang akan di las adalah sebagaimana Tabel 1 berikut ini [5].

Tabel 1. Komposisi Kimia Aluminum 1100-H18

\begin{tabular}{|l|c|c|c|c|c|c|c|}
\hline Unsur & Al & Si & Fe & Mn & Mg & Cr & $\mathbf{Z n}$ \\
\hline \% masa & 99 & 0,44 & 0,34 & 0,06 & 0,62 & 0,02 & 0,04 \\
\hline
\end{tabular}

Penelitian ini menggunakan parameter laju indentor las (V) yang tetap, 20mm/menit, sedangkan putarannya (Rt) dibagi menjadi 4 (empat) variasi yang berbeda, yaitu: 352, 490, 653, dan $910 \mathrm{rpm}$. Kedua parameter tersebut (V dan $\mathrm{Rt}$ ) dilakukan secara bersamaan, sehingga dihasilkan gesekan dan panas pada material pelat aluminum yang akan di las.

Urutan langkah yang standar pada proses FSW adalah sebagaimana dijelaskan pada Gambar 3 [5-6].

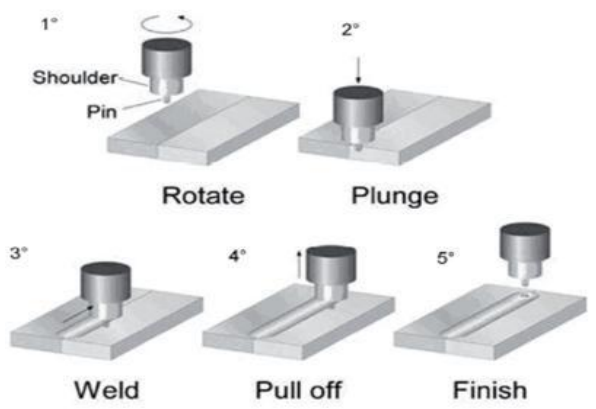

Gambar 3. Urutan langkah pengelasan FSW

Sesuai ilustrasi Gambar 3 di atas, proses pengelasan FSW dilakukan dalam 5 (lima) tahapan, yaitu: pertama, penyiapan dan pemasangan indentor (pahat) las pada bahu pencekam dan kemudian memberikan putaran pahat secara tetap. Tahap kedua adalah menempatkan indentor pada daerah lasan (weld line) yang merupakan batas antara dua benda kerja, sehingga dengan adanya putaran dan gesekan antara indentor dan benda kerja maka terjadilah panas.

Proses pengelasan merupakan tahap ketiga, dimana dilakukan setelah terjadinya panas yang cukup untuk mencapai suhu sekitar 0.8 Tc (titik cair) logam dasar (base metal, BM). Indentor kemudian dijalankan kearah mengikuti garis las. Pull off atau proses pengangkatan indentor las dilakukan setelah indentor las mencapai daerah ujung logam dasar. Terakhir adalah proses penyelesaian (finishing) dengan mematikan putaran dan mesin freis.

Tipe struktur mikro hasil pengelasan FSW yang baik, dapat dibagi dalam 4 (empat) daerah pengelasan, yaitu: logam dasar (base metal, BM), daerah adukan logam semi-cair (stir zone, SZ), daerah terpengaruh panas secara mekanik atau disebut thermo-mechanical affected zone (TMAZ), dan daerah terpengaruh panas (heat affected zone, HAZ) [6]. Dalam proses pengelasan gesek puntir, SZ merupakan daerah dengan temperatur yang paling tinggi, sehingga terjadi perubahan struktur mikro dan besaran butir dan proses rekritalisasi. Pada daerah TMAZ, umumnya terjadi pengkasaran butir, tanpa proses rekristalisasi dikarenakan temperaturnya yang relatif lebih rendah atau di bawah suhu rekristalisasi logam dasar. Selanjutnya, pada daerah HAZ, sebagaimana proses pengelasan lain maka panas las akan menyebabkan terjadinya pertumbuhan butir.

\section{HASIL DAN PEMBAHASAN}

Setelah dilakukanya proses FSW dengan empat jenis kecepatan putar indentor las, didapatkan gambar visual hasil pengelasan Al 1100-H18, sebagaimana foto spesimen pada Gambar 4.

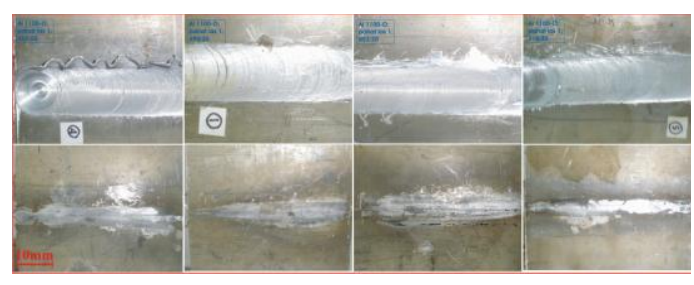

(a)

(b)

(c)

(d)

Gambar 4. Foto sampel bagian atas dan bagian bawah pelat Al 1100-H18 hasil FSW

Selanjutnya dilakukan pengujian mekanik untuk menentukan kualitas sambungan las berupa uji tarik, uji keras mikro, dan metalografi. Pengujian kekuatan tarik dilakukan dengan menggunakan mesin uji tarik Universal Testing Machine, dan hasil uji tarik ditunjukkan pada Gambar 5 dan Tabel 2, sebagai berikut.

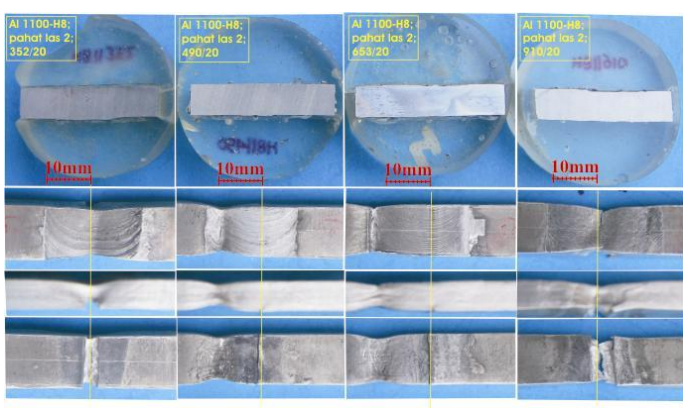

(a)

(b)

(c)

(d)

Gambar 5. Foto makro hasil uji tarik sampel FSW pada 4 putaran indentor berbeda: 352 (a), 490 (b), 653 (c), dan $910 \mathrm{rpm}$ (d) 
Tabel 2. Data Hasil Uji Tarik

\begin{tabular}{|c|c|c|c|c|c|}
\hline \multirow{2}{*}{$\begin{array}{l}\text { Putaran } \\
\text { (Rt), rpm }\end{array}$} & \multicolumn{3}{|c|}{$\begin{array}{c}\text { Letak } \\
\text { Perpatahan }\end{array}$} & \multirow{2}{*}{$\begin{array}{c}\text { Daerah } \\
\text { patah }\end{array}$} & \multirow{2}{*}{$\begin{array}{c}\text { Kekuatan } \\
\text { Tarik (Mpa) }\end{array}$} \\
\hline & $\mathrm{HAZ}$ & $\mathrm{SZ}$ & BM & & \\
\hline 352 & - & V & - & Bawah & 105,5 \\
\hline 490 & $\sqrt{ }$ & - & - & Tengah & 106 \\
\hline 653 & - & - & $\sqrt{ }$ & Tengah & 107 \\
\hline 910 & - & $\sqrt{ }$ & - & Bawah & 95,5 \\
\hline
\end{tabular}

Struktur mikro hasil pengelasan hanya diujikan pada proses FSW dengan parameter kecepatan transversal (V) $20 \mathrm{~mm} / \mathrm{menit}$ dan putaran indentor 653rpm, sesuai Gambar 6. Data struktur mikro tersebut menunjukkan adanya pembagian daerah (zonasi) yang jelas dan sesuai dengan literatur standar, sebagaimana hasil penelitian lain [4-6]. Data hasil uji keras mikro ditunjukkan pada Gambar 7.

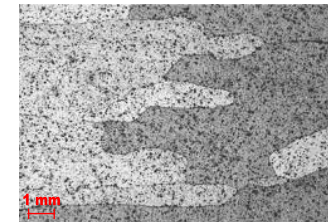

(a)

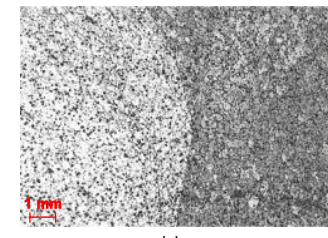

(c)

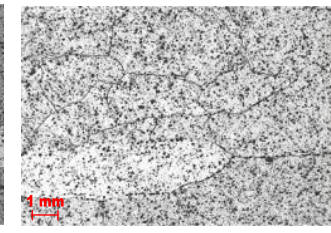

(b)

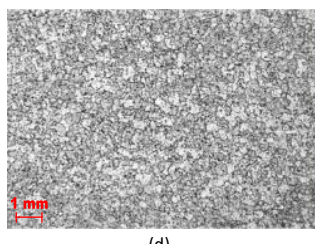

(d)

Gambar 6. Struktur mikro sampel hasil FSW pada $\mathrm{Rt}=653 \mathrm{rpm}$ dan $\mathrm{V}=20 \mathrm{~mm} /$ menit di daerah logam dasar (a), HAZ (b), TMAZ (c) dan SZ (d).

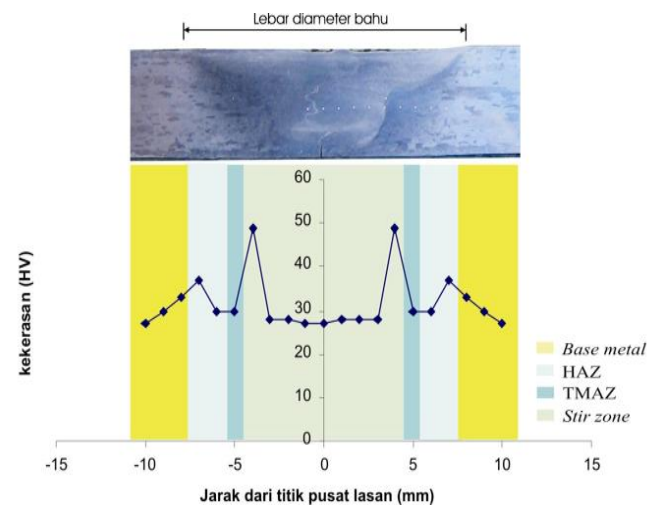

Gambar 7. Hasil uji keras mikro hasil pengelasan dengan kecepatan putar indentor $\mathrm{Rt}=653 \mathrm{rpm}$
Berdasarkan data yang didapat, secara umum menunjukkan bahwa semakin tingginya kecepatan putar indentor las, akan menghasilkan peningkatan angka kekuatan tarik hasil las, dimana kekuatan tarik maksimum didapatkan pada putaran indentor, $\mathrm{Rt}=653 \mathrm{rpm}$. Kekuatan tarik minimum didapatkan pada kecepatan putar (Rt) 910rpm. Pengamatan visual terhadap cacat las pada berbagai kecepatan putar indentor juga menunjukkan tren yang sama, dimana semakin tinggi kecepatan putar indentor akan cenderung menghasilkan visual hasil lasan yang semakin baik, dengan titik optimum pada Rt 653rpm.

Hal tersebut ditandai dengan berkurangnya cacat pengelasan yang terjadi, seperti: tidak terbentuknya pori, dan tidak terjadinya gelombang hasil las (surface tearing). Beberapa jenis cacat yang terjadi pada kecepatan putar yang terlalu rendah $(\mathrm{Rt}=352 \mathrm{rpm})$ dan atau pun terlalu tinggi $(\mathrm{Rt}=910 \mathrm{rpm})$ diperesentasikan pada tabel 3 .

Tabel 3. Jenis cacat pada pengelsan FSW

\begin{tabular}{|l|c|l|}
\hline Jenis cacat & Gambar & \multicolumn{1}{|c|}{ Penyebab } \\
\hline $\begin{array}{l}\text { Alur dan } \\
\text { gelombang } \\
\text { lasan }\end{array}$ & & $\begin{array}{l}\text { - Pergerakan } \\
\text { pahat tidak } \\
\text { kontinyu } \\
\text { - Kurangnya } \\
\text { panas awal }\end{array}$ \\
\hline $\begin{array}{l}\text { Permukaan } \\
\text { pecah } \\
\text { (surface } \\
\text { tearing) }\end{array}$ & & $\begin{array}{l}\text { - Tekanan bahu } \\
\text { dan gesekan } \\
\text { pahat las } \\
\text { kurang }\end{array}$ \\
\hline $\begin{array}{l}\text { Porositas } \\
\text { tersebar } \\
\text { (running } \\
\text { pore) }\end{array}$ & & $\begin{array}{l}\text { - Penghasilan } \\
\text { panas tidak } \\
\text { homogen }\end{array}$ \\
\hline
\end{tabular}

Selanjutnya, berdasarkan daerah patah lasan menunjukkan bahwa proses pengelasan dengan kecepatan putar 653rpm memiliki daerah patah di logam dasar, dimana menunjukkan bahwa hasil pengelasan lebih superior (baik) kualitas sifat mekaniknya. Sementara pada putaran lain terjadi patah di daerah $\mathrm{SZ}(\mathrm{Rt}=352 \mathrm{rpm}$ dan $\mathrm{Rt}=910 \mathrm{rpm})$ dan HAZ (Rt=490rpm). Hasil uji keras mikro pada kecepatan putar $\mathrm{Rt}=635 \mathrm{rpm}$ juga menunjukkan bahwa daerah SZ, HAZ, dan TMAZ memiliki angka kekerasan yang lebih tinggi dibandingkan (BM) dimana daerah patah uji tarik didapatkan. Hasil yang sama juga ditunjukkan oleh peneliti lain yang menyimpulkan adanya hubungan antara kecepatan putar indentor las dan kualitas hasil pengelasan [7]. 


\section{KESIMPULAN}

Berdasarkan data dan pembahasan terhadap hasil pengujian struktur makro, mikro dan uji mekanik terhadap hasil pengelasan aluminum seri 1100-H18, maka terdapat pengaruh signifikan antara kecepatan putar indentor las terhadap kualitas hasil pengelasan. Rt yang tinggi cenderung menghasilkan pembangkitan panas yang lebih baik bila dibandingkan pada Rt yang rendah, sehingga didapatkan hasil pengelasan yang lebih baik, hingga titik optimum tertentu. Dalam penelitian ini kecepatan putar indentor (Rt) 653rpm merupakan titik optimumnya. Kecepatan putar indentor las yang terlalu rendah maupun terlalu tinggi akan menghasilkan berbagai jenis cacat alur gelombang hasil lasan, permukaan yang pecah (surface tearing) dan porositas yang tersebar (running pore).

\section{UCAPAN TERIMA KASIH}

Penulis mengucapkan terima kasih kepada Bapak Asep Hermanto atas bantuan editing makalah artikel ilmiah ini.

\section{DAFTAR PUSTAKA}

1. Timings, R. L., 1998, "Engineering Materials Technology”, $2^{\text {nd }}$ edition, Prentice Hall, New Jersey, USA.

2. Biswas, P. danMandal, N. R., 2011, "Effect of Tool Geometries on Thermal History of FSW of AA1100", Supplement of TheWelding Journal, July 2011.

3. Nandan, R.,dkk., 2008, "Recent advances in friction-stir welding - Process, weld structure and properties", Progress in Materials Science 53: 980-1023.

4. Okamura, T. dan Wiryosumarto, H., 1996, "Teknologi Pengelasan Logam", Pradya Paramita, Jakarta

5. Nakata, K.,dkk. 2000. "Weldability of High Strength Aluminium Alloys by Friction Stir Welding”. ISIJ International, Vol. 40, supplement. pp. S15-S19

6. Jayaraman, M., dkk., 2009, “Optimization of process parameters for friction stir welding of cast aluminium alloy A319 by Taguchi method", Journal of Scientific \& Industrial Research, Vol. 68 January 2009, pp. $36-43$.

7. Sudrajat, A. F. P., dkk., 2012, "Analisis Sifat Mekanik Hasil Pengelasan Aluminum AA 1100 dengan Metode Friction Stir Welding (FSW)”, Jurnal ROTOR, Vol. 5 No. 1. 